European working time directive

\section{The European working time directive P Black}

\section{A British perspective}

T he European working time directive (EWTD) is a directive of the European Union within the umbrella of health and safety legislation. The directive was enacted in UK law, from l October 1998. ${ }^{1}$ The main features of the legislation relate to the average maximum numbers of hours that could in law be worked in a week, the duration and timing of rest periods, days off, and paid leave.

The EWTD applied to all medical staff, except doctors in training - that is, the house officer and specialist registrar grades. It is not widely appreciated that all other grades of medical staff are bound by this legislation unless they specifically, and individually "opt out."

An amending directive was issued in $2000,{ }^{2}$ removing the exemption of doctors in training from the EWTD, to take initial effect in August 2004, when the average weekly working time had to be reduced to 58 hours. Thereafter, in August 2007, this should be reduced to 56 hours per week, and in 2009 to 48 hours. This was not optional, but was a legal requirement and breaches of this legislation are subject to significant financial penalties, to be imposed on the employing trusts. Compliance is checked by continual monitoring.

Not surprisingly, there was a flurry of activity, and a plethora of documents, guiding and advising trusts on how to deal with this issue, both from the Department of Health, and the royal colleges. Crucial to determining how trusts would respond to this was the definition of work, when the resident was on call-that is, was asleep, doing on-call work, or resting. Luckily for us all, help was at hand in the shape of a specific challenge to the directive, known as the "Simapp" case. This ruled that "resident on-call" was work, whether engaged in clinical activity, sound asleep, or any other activity. The specific rest requirements after a period of work, were also challenged, and clarified by the "Jaeger" judgment, which applied to rest periods after a period at work. Specifically, that a rest period must be taken immediately after the work period to which it related.

It was rapidly apparent that the responses to this would be varied, depending on type and size of hospital, and discipline. Ophthalmology, in general, was in a fairly favourable position. Most district general hospitals (DGHs) had provided a 24 hour emergency service. Providing there is general medical cover on site, it is not necessary for ophthalmologists to be resident on-call, even though accommodation was on site. This had some financial repercussions for those individuals on call, but in general had little effect on the running of departments providing six doctors could be found to be in the first tier of the on-call system. Even then, it is necessary for these doctors to reduce the number of hours worked (and trained) during the normal working day.

Fewer doctors meant a greater reduction in hours worked during the normal working week. A few small units found themselves amalgamating with their neighbours to maintain an emergency service round the clock, a few abandoned any thoughts of providing 24 hour cover, and a very few provided consultant first on-call cover after $10 \mathrm{pm}$ or midnight.

\section{We are sitting on a bomb that is ticking. The explosion will occur in 2009}

The same could not be said of large "stand alone" units. Here, there was a requirement for resident doctors on site after normal working hours. These would, of necessity, be ophthalmologists, and were in the same position as front line acute specialty services in DGHs. The responses were predictable. It was necessary to work a shift system of resident on-call medical staff, utilising medical staff who were used to being in the second tier, since the numbers required were of the order of $8-10$, in the rota, perhaps necessitating the abolition an intermediate tier. Moves were made to increase the number of specialist registrars to provide added numbers within the tiers of the on-call rota, and to meet the first wave of EWTD hours.

Little thought was given to the consequences of this action, specifically that it would destabilise workforce planning, already tottering under short term political initiatives, in which there was no strategic thought whatsoever. Specialist registrars are still embryonic consultants, although for how much longer this notion will continue is debatable. It remains the view of our royal college, if not the politicians.

What has been the effect of the EWTD so far? The intention was to improve the working lives of doctors in training, and to increase patient safety, by removing tired doctors from front line care. Training takes place, mostly, during the normal working day. Some, but not much, takes place in the evenings. Those not on a shift system are able to attend training sessions, theatre or clinic, or more informal sessions. Even with the current level of work dictated by EWTD, time off during the normal working week has to take place to fulfil the legal requirements of UK law. Training time is part of work within the meaning of the law. Those on the night shift complain that there is little by way of training component to that part of their work pattern. There is no team spirit and little supervision. Firms may be old fashioned, but the leader (consultant) knew her or his trainees, knew the strengths and weaknesses of those in training, knew where to apply the carrot and stick, and knew who could or was able to step up a gear, and who could not. This is diluted with a full shift system.

Continuity of patient care has gone out of the window for those unfortunate enough to have to work a full shift system. Handovers, often of dubious quality, occur at the end of a night on call. The next night, the patient has left the ward, either through natural selection, or more likely because of the perpetual bed juggling that is a feature of hospital life these days.

Has patient care improved? I don't think so. But these doctors get a day's rest before the next night on call. They must be rested and therefore are safer. The evidence is that this is not the case. A shift system, particularly the night shift, is draining because of the disturbance of the rhythm of normal activity. There are consistent complaints from doctors within the training system that the EWTD impedes training. ${ }^{3}$ Surgical trainees complain that their exposure to surgery is handicapped by this system. The amount of surgical time available to trainees has diminished: it is reasonable to deduce that this has a detrimental effect on surgical ability, which is not just about fulfilling a curriculum, but about experience, and being exposed to as many problems as possible before surgical independence, and before a problem becomes their problem. ${ }^{4}$ 
The obvious solution to training is to extend the working day; simple. Who will supervise? Most consultants are already working up to their legal maximum, 48 hours, or 12 "programmed activities" (PAs). Why not appoint more? At present the evidence is that new appointments in ophthalmology have plummeted, as the new financial structure of our NHS unfolds. Even replacement posts are being advertised as short term posts as trusts face considerable financial uncertainty. The support structure is just not in place, with most non-medical staff constrained by a 37 hour working week, and no money to appoint new staff, even if they were available.

Consultants have to shoulder an added burden because their junior support for that day has run out of hours. In this respect, ophthalmology has not, so far, come out of this too badly, but things are about to change: next year the EWTD will define the maximum average working week as 56 hours. It is probable that most units will cope with this. The adjustments to departmental working practices, already made, will be relatively minor. It will mean each doctor in training working 2 hours less, on average, per week. There is likely to be some rationalisation of emergency services between adjacent acute units. However, the crunch will come in August 2009, when the average working week must be reduced to 48 hours.
The first and major casualty in ophthalmology will be the on-call services. A Royal College of Ophthalmologists survey carried out in 2004 indicated that in August 2007, when the 56 hour limit comes in, some $25 \%$ of departments will no longer have sufficient resources to provide 24 hour cover. In August 2009, 50\% of all UK eye departments will be unable to fulfil the EWTD without abolishing after-hours work, and abandoning all hope of providing continuing cover for their locality.

Rationalisation of services, on a subregional basis, will be a necessity if doctors in training are to have a reasonable working week, when the trainers are available (and the patients). It will of necessity be a shorter working week, it might drive doctors out of surgical training. $^{5}$ Even in major cities, it is probable that some rationalisation of out of hours services will become necessary, however uncomfortable and politically difficult that may be.

The aims of the EWTD are laudable. The effect has been damaging, especially to training, and to some extent to continuity of patient care, perhaps not so much in ophthalmology. It does not appear to have the desired effect of enhancing working lives of doctors, nor of improving patient care, in general. ${ }^{6} \mathrm{~A}$ proposal for a new directive of the European Parliament is pending, specifically with regard to definitions of "on call time," and "inactive on-call," and new provisions regarding the "opt-out." Submissions were sent in October 2004. It is not known when the European Parliament will reach a decision. There is clearly an urgent need for there to be changes to the definition of work when a resident is on call and for there to be a relaxation of the opt-out rules. Modernising Medical Careers envisages that all UK graduates will enter some form of formal higher medical training. They will all be subject to the EWTD. They cannot opt out at present. We are sitting on a bomb that is ticking. The explosion will occur in 2009. It is essential that eye departments start to plan now!

Br J Ophthalmol 2006;90:1082-1083.

doi: 10.1136/bjo.2006.097212

Correspondence to: Peter Black, James Paget Hospital, Lowestoff Road, Gorleston, Norfolk NR31 7PW, UK; peter.black8@virgin.net

\section{REFERENCES}

1 UK Parliament 1998. The Working Time Regulations 1998 [online]

2 Council of the European Union 2000. Directive 2000/34/EC of the European Parliament and of the Council of June 2000, amending Council Directive 93/104/EC [online].

3 Chandra A. A junior doctor's dismay at a full shift system. Med Educ 2004;38:455-6.

4 Anwar M, Irfan S, Daly N, et al. EWTD has negative impact on training for surgeons. BMJ 2005:331:1476.

5 Morris-Stiff GJ, Sarasin S, Edwards P, et al. The European Working Time Directive: one for all and all for one? Surgery 2005; 137:293-7.

6 British Medical Association. Cohort study of 1995 medical graduates. 10th Report. London: BMA, 2005.

\section{European working time directive}

\section{S Omland}

\section{A Norwegian perspective}

W orking time limits in the Nordic countries, with their long, social democratic traditions and strong labour unions, are among the world's lowest.

As early as 1919 the Norwegian parliament passed a statute enacting a limit of 8 hours' work a day for a maximum of 6 days a week. The general Norwegian working week has later been reduced to 5 days, with Saturdays and Sundays free.

Exempt from these limitations have been professions demanding 24 hour reaction capability, such as hospital doctors, who for many years had virtually unlimited working hours, very much like in the present British system.

More restrictive rules have gradually been established, and the Norwegian hospital doctor's general working week is now limited to 38 hours. Doctors consenting to work up to 50 hours a week are, however, allowed to do so. Maximum continuous on-call duty is limited to 19 hours.

The exemption from the 38 hour limit has had the effect that most hospital doctors work substantially more hours, many as much as 50 hours a week, and tacitly, a few even longer. A particularly exhausting constellation in the Norwegian system is the combination of an ordinary working day, tied directly to on-call night duty passing over into the first part of the next working day.

A system demanding and expecting top intellectual and professional performance, from a doctor becoming more and more tired, has been the most weighty argument for the introduction of shorter, but hopefully more efficient, working hours in Norwegian hospitals.

Among foreign colleagues I have met quite a variety of views of Norwegian working time rules, ranging from the supercilious to the envious. One British colleague, obviously having noticed our short working hours, politely remarked that it must be rather difficult to become a good doctor in a land where so little working time is devoted to the execution of one's profession.

Another Briton, with whom I worked for some time in Oslo, expressed in a more direct way that the least positive aspect of working as a hospital doctor in Norway, was the short working hours. 